\title{
Spatial Visualisation
}

\author{
Jiří Pánek
}

\begin{abstract}
According to the International Cartographic Association (ICA), Cartography is the discipline dealing with the art, science and technology of making and using maps; while a map is a symbolised representation of geographical reality, representing selected features or characteristics, resulting from the creative effort of its author's execution of choices (ICA 2018). This subchapter is focused on step-by-step procedure on how to create a thematic map, which are the basic cartographic elements and how to select the optimal visualisation method.
\end{abstract}

\section{Keywords}

Cartography · Spatial visualisation - QGIS . Choropleth maps $\cdot$ Thematic maps

\subsection{Introduction}

For creating a map in a vector-based model one can use points, lines and polygons. All of the features have parameters (Fig. 9.1), that can be changed in order to create unique visual interpretation. In 1967 Jacques Bertin proposed an

J. Pánek $(\bowtie)$

Department of Development and Environmental Studies, Palacký University Olomouc, Olomouc, Czech Republic e-mail: jiri.panek@upol.cz original set of "retinal variables" in Semiology of Graphics (Bertin 1967):

- Position

- Size

- Shape

- Value (lightness)

- Colour hue

- Orientation

- Texture

The ultimate combination of the variables above allows the author (cartographer) to create a unique visual outcome of his/her work - a map. On the following pages we will have a look on what basic types of maps can be used and how to prepare them in open-source software QGIS (QGIS.com 2018).

The most widely used methods of expression in thematic cartography are choropleth maps. These are maps in which the intensity of the phenomenon is expressed using colour fill or raster/pattern in polygon, converted to a unit of the surface of the observed territory. The other options for spatial visualisation are Cartograms, thematic maps, where variables such as travel time, population, or GNP are substituted for land area or distance. In case of Cartograms geometry or space of the map are distorted. Another visualisation method would be proportional symbols, that would use points or lines to visualise the variable. 
Fig. 9.1 Bertin's visual variables. (Source: Authors)

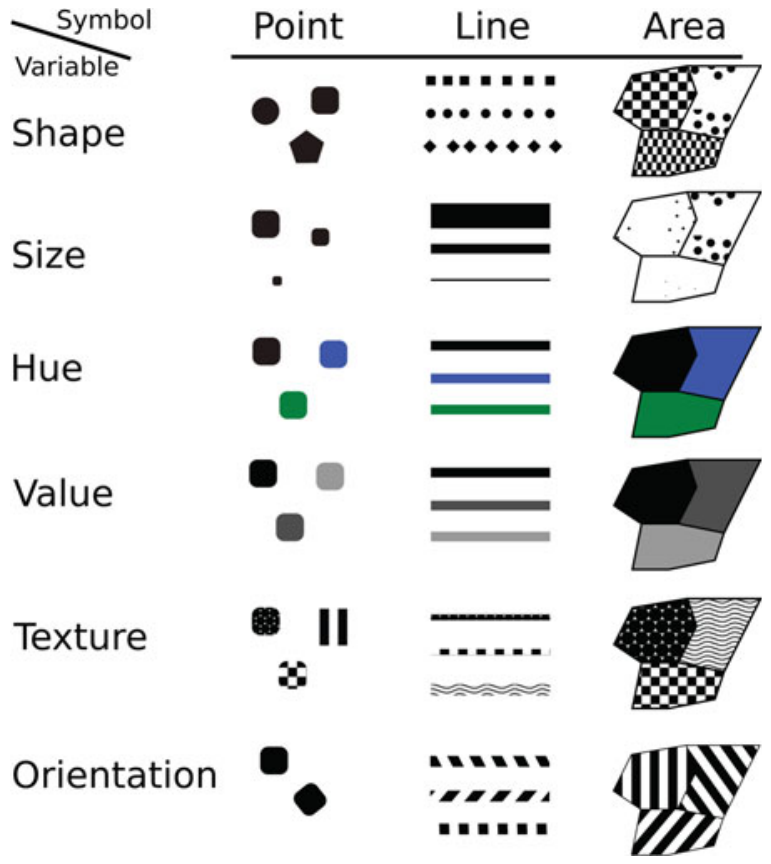

\subsection{Creation of the Choropleth Map}

From a strictly cartographic perspective choropleth maps express the selected phenomenon converted into a surface unit - e.g. population density (number of inhabitants $/ \mathrm{km}^{2}$ ) or density of road network (total length in $\mathrm{km} / \mathrm{km}^{2}$ ). Geographers, demographers or sociologists however often need to express the intensity of a phenomenon (even if related to a certain surface) converted to a unit of a non-surface character, most frequently in the form of percentage or per thousand share - e.g. proportion of economically active persons in total population of the selected locality (\%) or gross birth rate (\%o). As mentioned above, choropleth maps express only relative values. It is a cartographic error if data on absolute values of the observed phenomenon is displayed - e.g. number of inhabitants in districts or number of small hydroelectric power stations in catchment basins. In these cases it is not possible to speak of a choropleth map in the geographical or cartographic sense of the word.
In geographical practice, the creation of a choropleth map is performed most frequently in territories which can be delineated by various types of boundaries. This primarily concerns boundaries of an administrative character (e.g. states, regions, cities), but also boundaries delineated on the basis of either selected socio-economic geographical aspects (e.g. commuter belts, urban agglomerations) or physical-geographical aspects (e.g. catchment basins, geomorphological units).

However, it is also possible to encounter the method by which the entire territory is covered by a network of regular cells of identical size, and the data expressing the intensity of the observed phenomenon is then presented for the individual cells of the aforementioned network.

The method of expression of the choropleth maps is frequently used in combination with the proportional symbol method (see Sect. 9.4). This method of presenting data has a great advantage in simultaneous display of relative (choropleth maps) and absolute (proportional symbol) values of the phenomenon of the observed territory, thanks to which the user is able to determine more information from a single map. 


\subsubsection{Creating the Choropleth Map in QGIS}

Choropleth maps are created using the offer Properties (click with the right button on the name of the layer and select Properties). In the window you open the Symbology (Fig. 9.2) menu, where the visualisation of the layer can be defined. A number of options are available here for visualization of data:

- No symbol

- Single symbol

- Categorized

- Graduated

- Rule-Based

- Inverted polygons

- $2.5 \mathrm{D}$
In order to create the choropleth map "Categorized" or "Graduated" are the most often used options within the symbology menu. The main difference between categorized and graduated options is that categorizes works with numeric as well as text values and assigns each value a unique symbol/colour - hence it is more suitable for qualitative data. On the other hand, graduated scales work with number fields only and are most often used for quantitative values.

\subsubsection{Graduated Choropleth Map}

In creating the example of density of population map graduated option is selected. The attribute from which the choropleth map is created is selected in the column offer. The program will automatically sort data into categories (equal interval is a default option) and allocate a colours

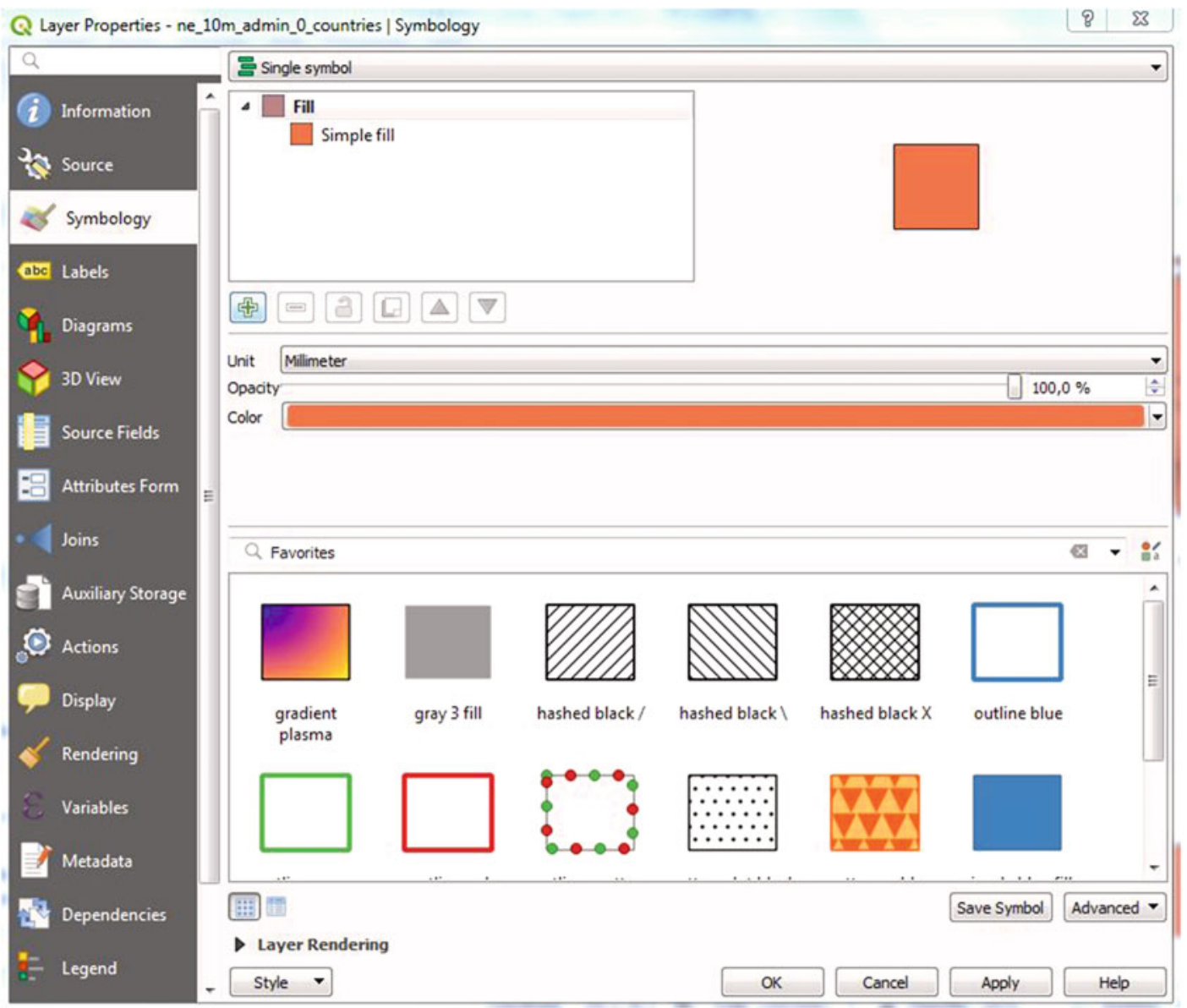

Fig. 9.2 Symbology menu in QGIS. (Source: Authors) 


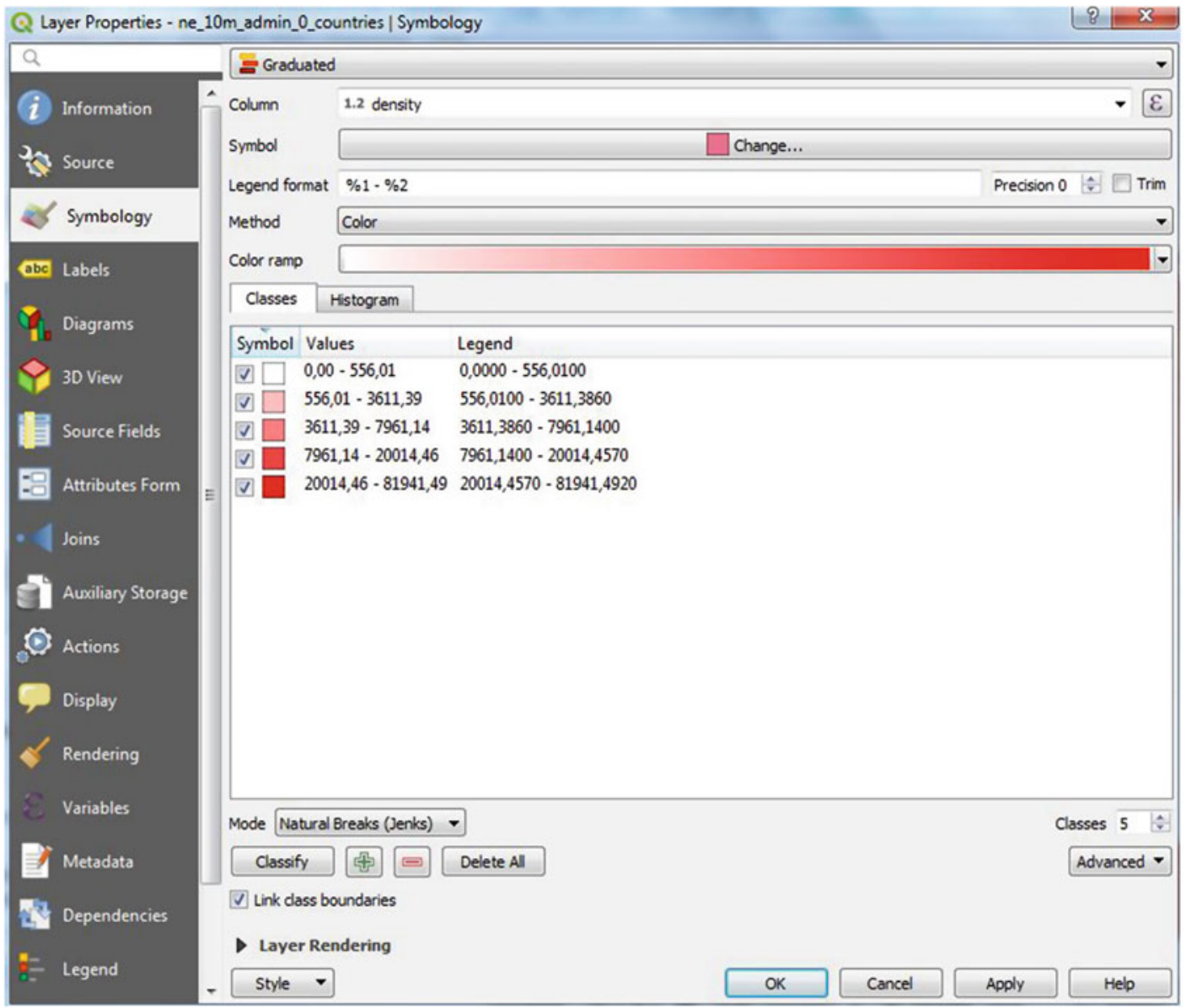

Fig. 9.3 Basic settings within the graduated option. (Source: Authors)

to it (Fig. 9.3). All these pre-set settings can be changed freely according to the user's requirements.

One has to be careful while selecting the "Mode" of data distribution into the bins, as there are tremendous differences between Equal interval, Quantile (Equal count), Natural breaks, Standard deviation and Pretty breaks modes.

Equal Interval divides the dataset into bins that have the same size without taking into account how many features is in each bin. Quantile has bins with equal number of cases in each bin, without taking the size of the bin into account. Natural breaks divide the dataset into the bins based on the histogram by seeking to minimize each class's average deviation from the class mean, while maximizing each class's deviation from the means of the other groups. Standard deviation makes equal intervals from the input data's distance from the average value. If you use an input column which has enough data below the mean to make more than one category, it will. The last mode is called Pretty breaks and it is based on the statistical package R's pretty algorithm. It is a bit complex, but the 'pretty' in the name means it creates class boundaries that are round numbers.

Adjustments to the classification of values into intervals are made by selecting the offer Classify or Histogram. In the section Values one can simply rewrite the Break Values to the required limit values. The number of displayed classes can be set in the offer Classes. These characteristics, like the histogram, serve for setting the optimum 
intervals. All settings are performed after clicking the button $O K$ or Apply.

The description of the interval which appears in the legend can easily be adjusted by clicking on the required value in the Legend field. The range of colours used can be adjusted using the offer Colour Ramp, which contains a large number of predefined colour ranges. After clicking on the Apply button the changes are made in the data field.

Creation of Choropleth maps is subject to fundamental cartographic rules. Amongst the most important are: the scope of intervals should be logical (e.g. linear growth, exponential, decimal categories etc.); the number of elements in each interval of the cartogram should be approximately the same; use the smallest possible number of intervals (if a layer has 30 elements it is not suitable to use 10 intervals) and use corresponding colours (it is not suitable to use black, the selected colour should correspond to the map topic). For further information one can read (Field 2018) (Fig. 9.4).

\subsubsection{Categorized Choropleth Map}

When working with qualitative values, such as country names, one cannot use graduated colour ramps, but unique random colour schemes. While creating the political map of a given region cartography follows the Five colour theorem or the Four colour theorem. Both of them state, that a given plane separated into regions, such as a political map of the counties of a state, the regions may be coloured using no more than four/five colours in such a way that no two adjacent regions receive the same colour. While the five colour theorem was proved already in the 1800 s, the four colour theorem was proved in 1976 by Kenneth Appel and Wolfgang Haken, but only after many false proofs and counterexamples. It was the first major theorem to be proved using a computer. Initially, their proof was not accepted by all mathematicians because the computerassisted proof was infeasible for a human to check by hand. Since then the proof has gained wide acceptance, although some doubters remain. (Robertson et al. 1996).

By default, QGIS cannot work with the theorems mentioned above and if the user decides to create a political map for example of Africa, s/he will end up with 54 states coloured by 54 different colours (see Fig. 9.5).

In order to apply the colour theorems mentioned above the user has to prepare the data by

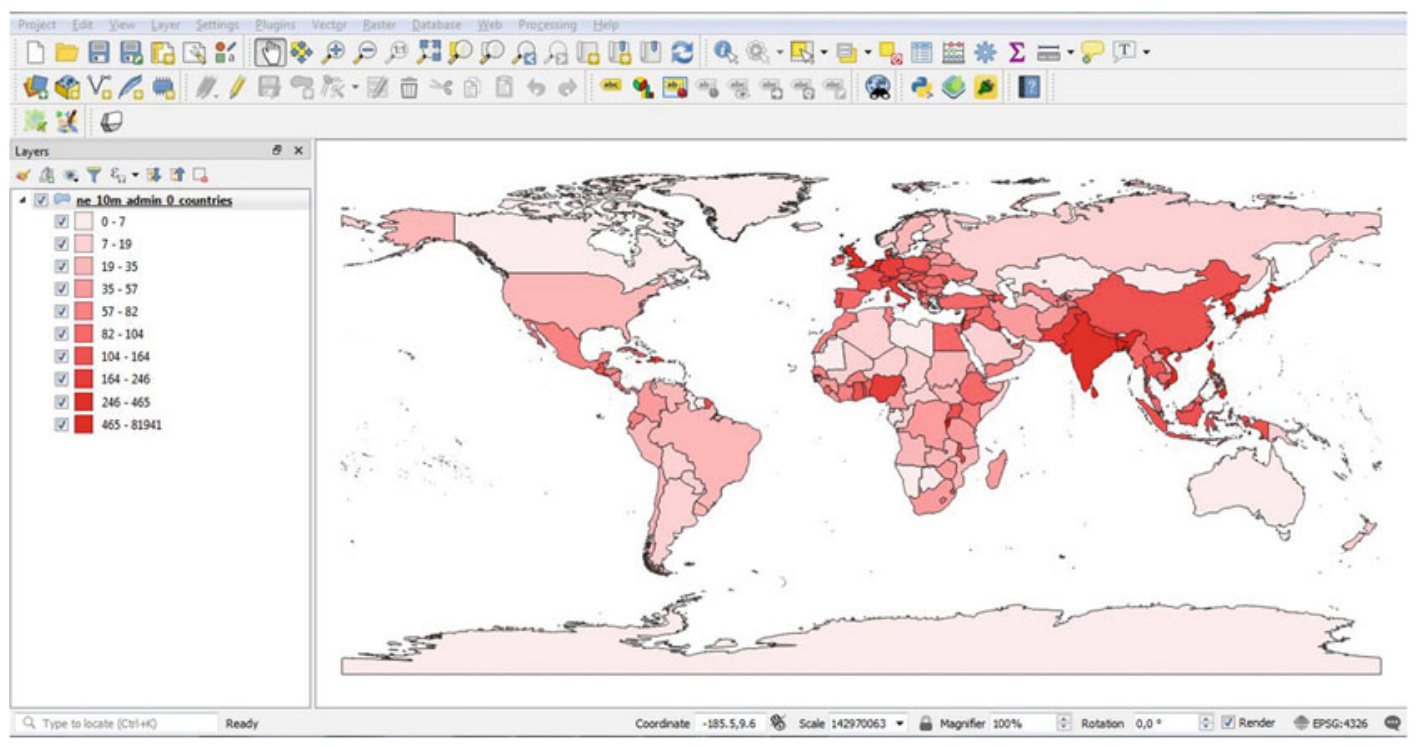

Fig. 9.4 Example of population density visualisation via Choropleth map using Quantiles with ten bins. (Source: Authors) 


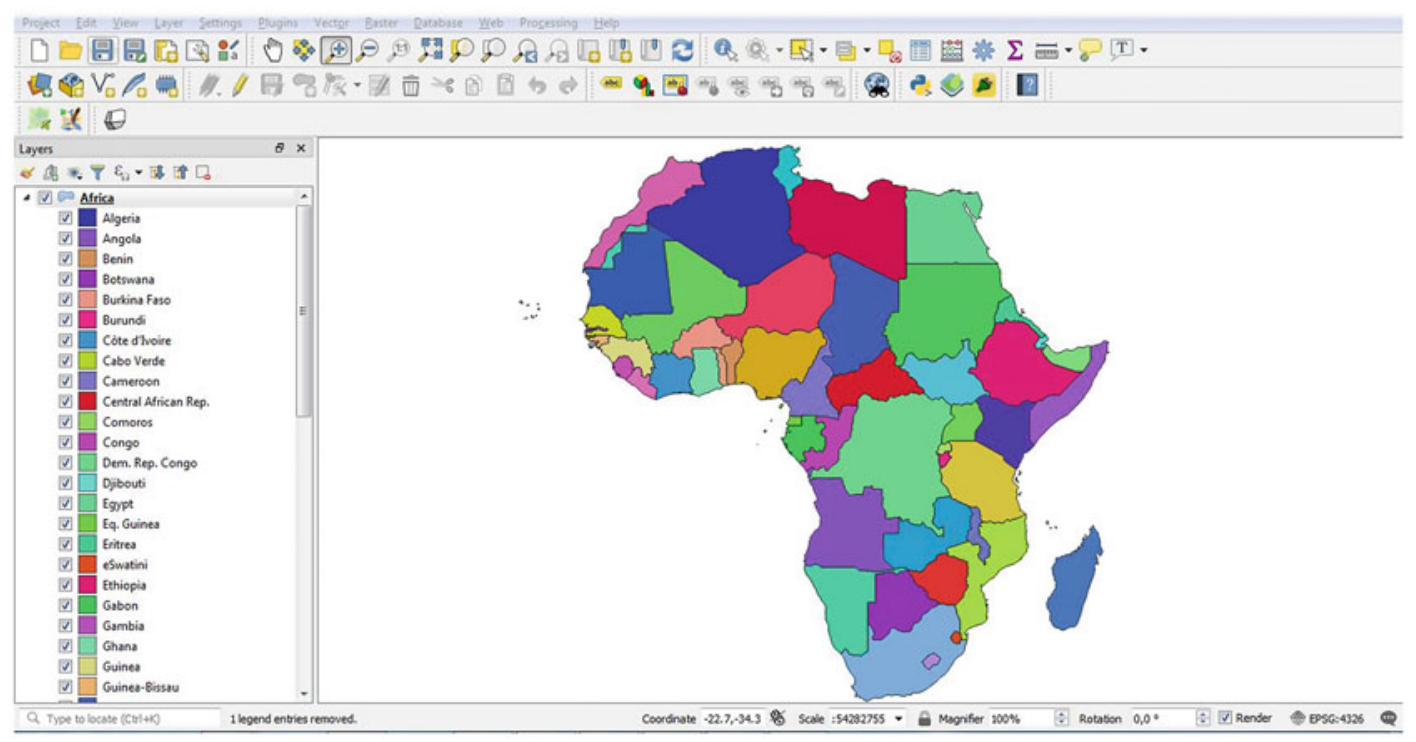

Fig. 9.5 Example of 54 coloured political map of Africa. (Source: Authors)

a Topological Colouring tool in the Cartography Toolbox (Fig. 9.6a), where a certain number of colours can be set (Fig. 9.6b). This toolbox will create a new column within the attribute table, which will contain a numeric value (1-4 for four colour theorem, 1-5 for five colour theorem), etc. (Fig. 9.7).

\subsection{Raster Fill Options}

According to Veverka and Zimová (2008), a raster is a method of expressing qualitative and quantitative characteristics of planar phenomena using regularly or irregularly spaced point or linear cartographic symbols. According to Čapek et al. (1992), a raster is a set of graphic elements (points, lines, letters, numerals) which are repeated and spaced around a certain part of a surface, forming a pattern. It is used both in black and white maps, where it replaces colour, and in colour maps, in which it supplements colour where a number of areas overlap.

Rasters can be divided as follows:

- according to geometrical character: point, line;

- according to spacing of symbols: regular, irregular;
- according to version: colour, black and white;

- according to use: qualitative, quantitative.

A raster formed by patterns or points (point raster) is called a pattern raster, and may differ in its shape, density, dimensions and layout. A linear raster is distinguished by the concurrent layout of lines (sometimes indicated as hatches) leading in one more directions (crossing). Lines may differ in their shape, thickness, density and orientation, see Fig. 9.8. The main use of a point and linear raster is on thematic maps.

A qualitative raster is used to illustrate the qualitative differentiation of the expressed phenomenon, thus its categories. It may for example concern the type composition of a forest, the predominant nationality composition, a geological map etc. Point and linear symbols in regular spacing are most frequently used for qualitative rasters, exceptionally also with irregular spacing.

For quantitative differentiation of the expressed phenomenon a quantitative raster is used, i.e. the degree of intensity of the phenomenon. For example population density, hectare yields etc. Unlike a qualitative raster, a quantitative raster expresses relative values.

The QGIS program offers several options for the visualisation of data into maps using rasters. 
a

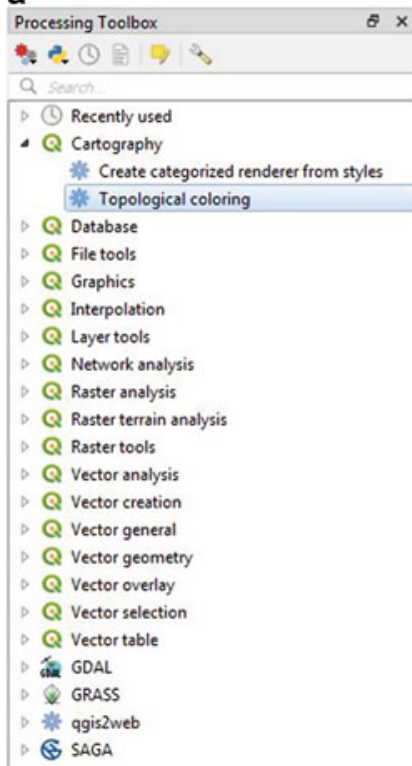

b

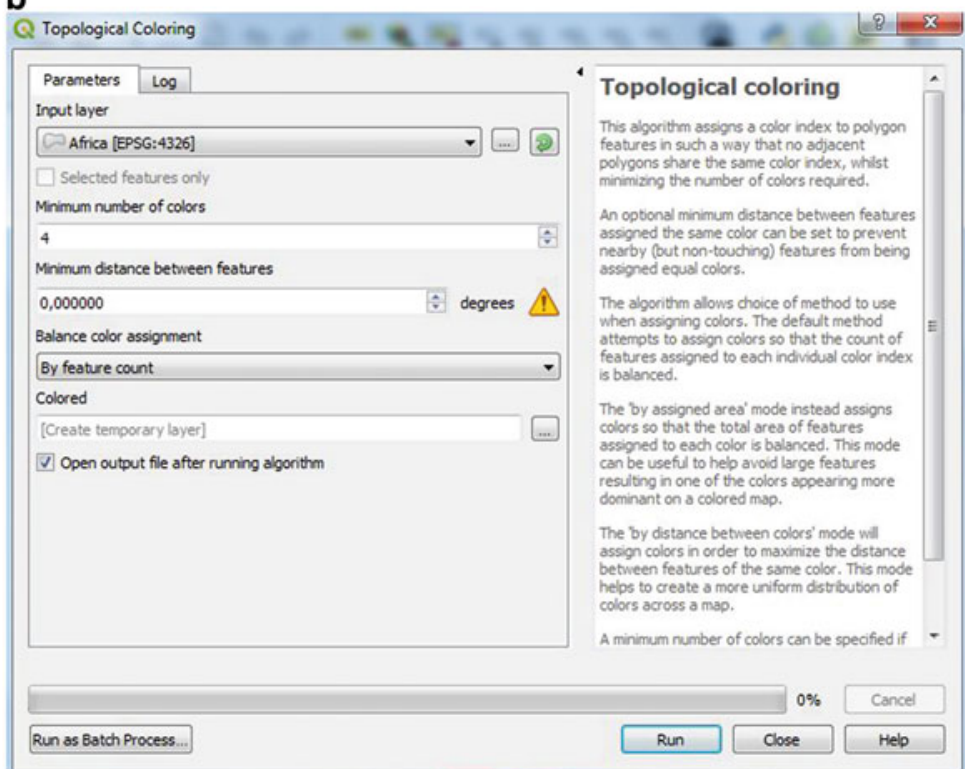

Fig. 9.6 (a) Topological colouring tool in the Cartography toolbox, (b) Setting of the Topological colouring tool. (Source: Authors)

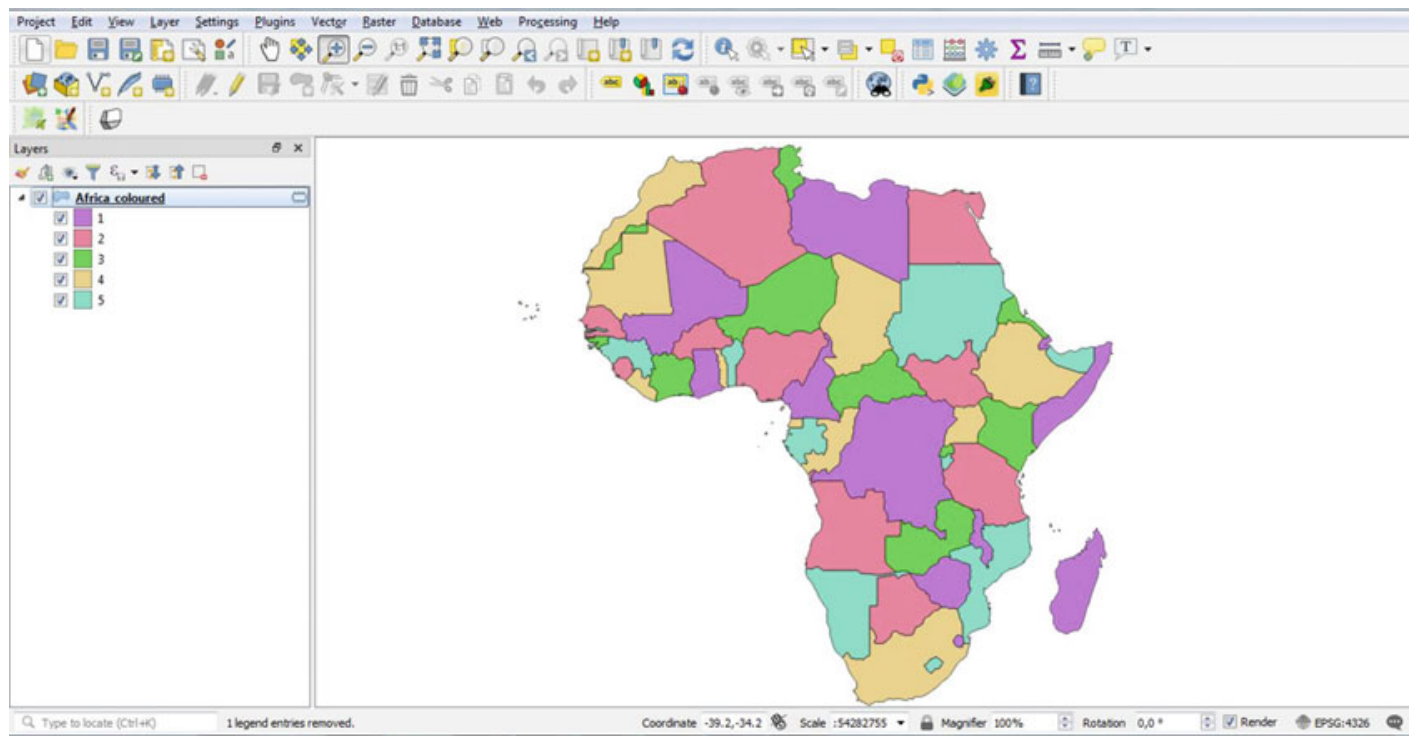

Fig. 9.7 Political map of Africa with using only five colours. (Source: Authors)

A simple example of a qualitative raster may be a different land use visualisation (Fig. 9.9). Unlike in other GIS software creating a raster fill is not a default option, but the raster has to be created by single line or point elements and by combining them, changing the size, orientation, offset, etc. (see Fig. 9.10). 

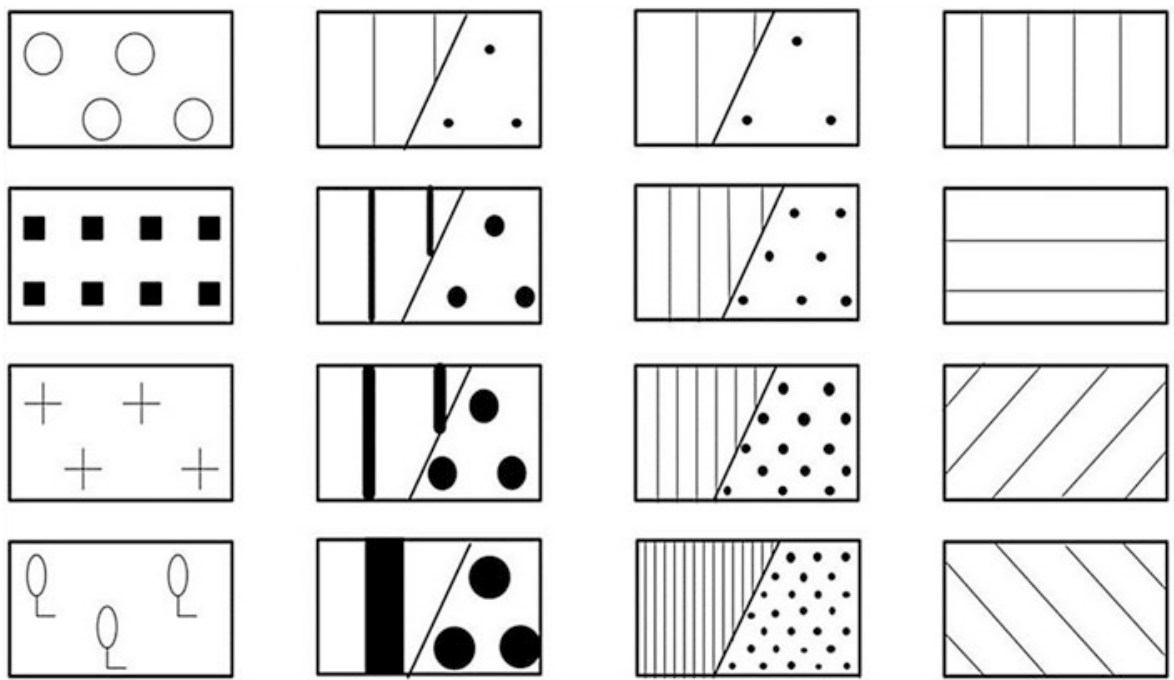

Fig. 9.8 Raster parameters. (Source: Authors)

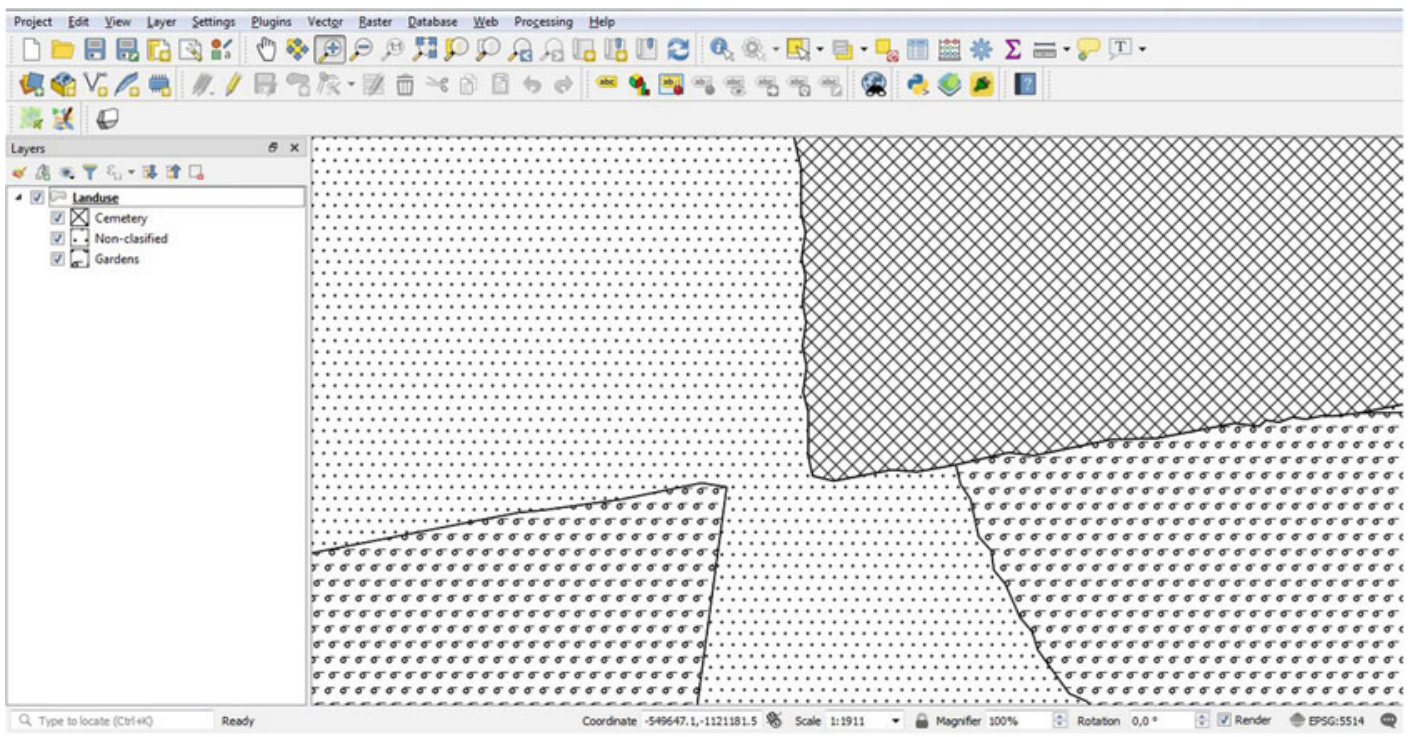

Fig. 9.9 Example of qualitative raster. (Source: Authors)

\subsection{Proportional Symbols}

According to Voženílek and Kaňok (2011), proportional symbols are used on maps with partial territorial units into which statistical data (absolute values), mostly of a geographical character, is illustrated by means of diagrams. Unlike choropleth maps, values in proportional symbols are always expressed in absolute form. An exception is the structure of a certain character, where the values are mostly stated in percentages (Čapek et al. 1992). Čapek et al. (1992), and Voženílek and Kaňok (2011) divide proportional symbols into three types: point, linear and planar (or planar structural). 
Fig. 9.10 Example of creating raster via symbol selector. (Source: Authors)

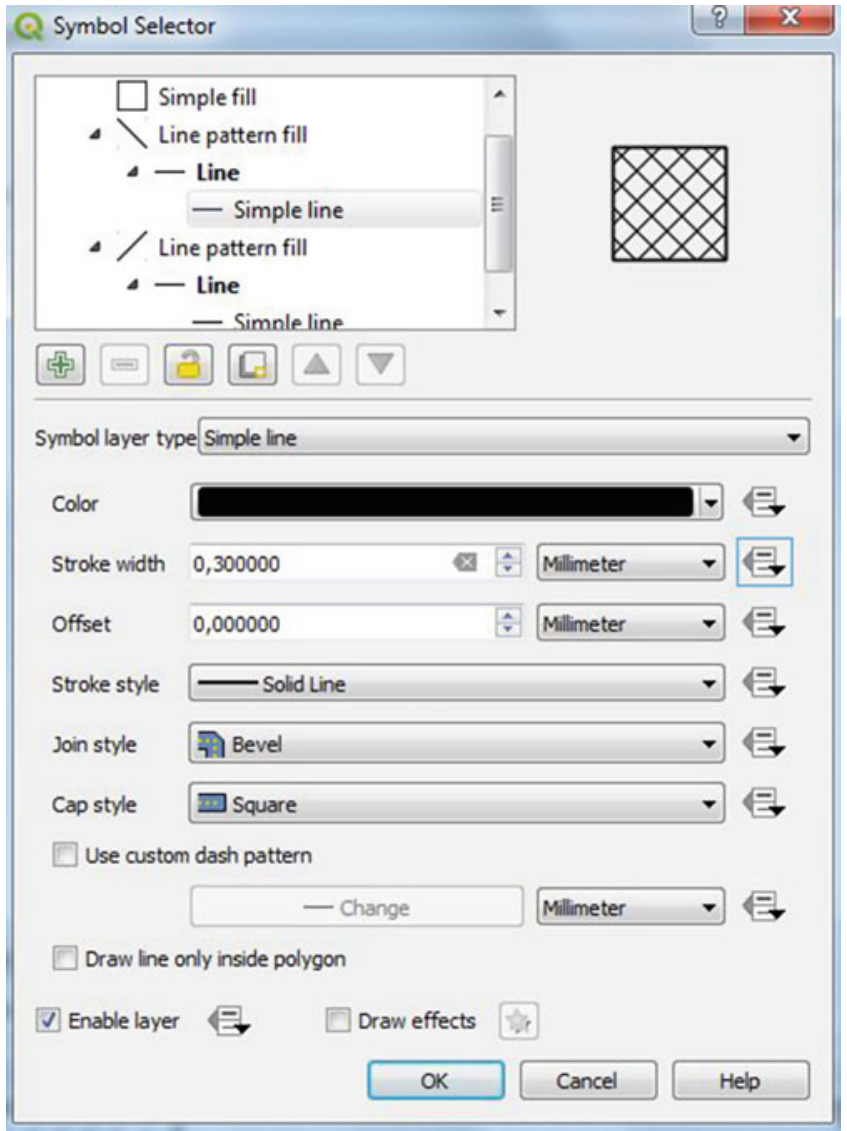

\subsection{Method of Graduate Symbols}

Simple graduated symbology is dealt within the QGIS program by the offer Symbology (similarly as raster above). The symbols can be graduated by colour (Fig. 9.11a) or by size (Fig. 9.11b). One can easily see, that for a larger number of features, like cities on a whole continent, colour is a better solution than size. On the other hand, when working with fewer features, the size option can be more optimal.

\subsection{Using Charts to Visualise Proportions}

Proportional symbols visualise relations between two or more counts, such as age distribution in the population as a percentage of total population. To display the proportional relationships in QGIS is via the menu Diagrams in Layer Properties. Among others, Pie Charts (Fig. 9.12a) and Histograms (bar/column chart - Fig. 9.12b, c), are available options. Like the Proportional Symbol map, the Pie Chart map plots a single symbol usually at the centroid of each geometry. Each chart can vary in size, representing a certain value - such as population, while the division of the chart will represent the age distribution within the population. Similarly to Pie Charts, Histograms can visualise proportional values. Histograms can be oriented as a bar or a column graph.

\subsection{Cartograms}

A cartogram is a specific type of map, where the theme (such as travel time, wealth, or population with HIV/AIDS) is substituted for land area or 
a

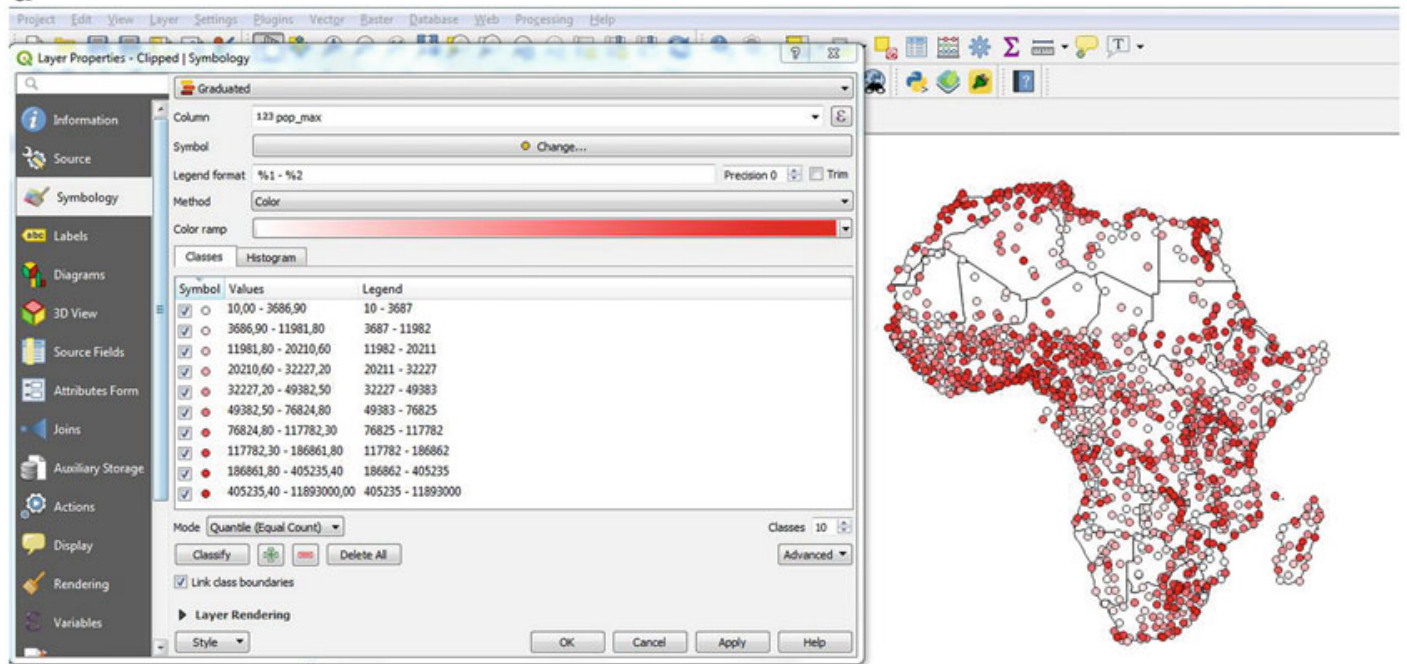

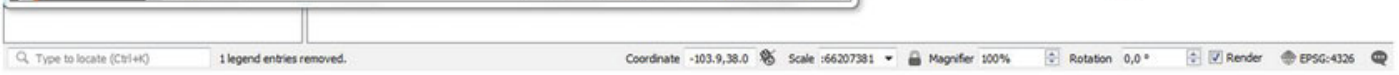

b

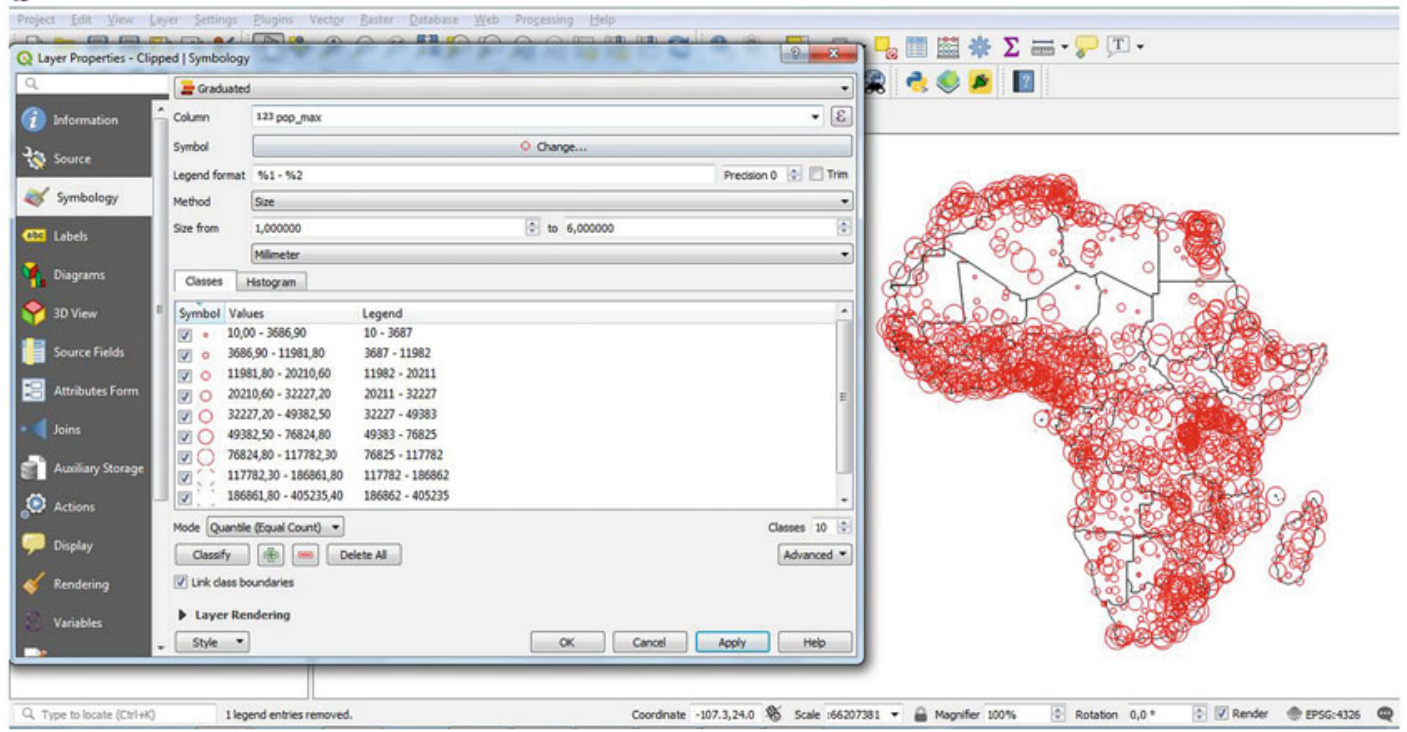

Fig. 9.11 (a) Visualisation by colour. (b) Visualisation by size (source: Authors)

distance. The geometry is distorted in order to convey the information of this alternate variable.

\subsection{Map Composition}

Map composition as the layout of the basic structural map elements is a result of the cartographic creativity of the author. The visual presentation
(Fig. 9.13) should follow some cartographic rules and its purpose, scale, map sheet format etc.

There are five main elements of a map layout, that should be present in every map:

- Name/Title

- Scale

- Legend

- Map field

- Imprint belong 
Fig. 9.12 Visualisation of same data as (a) Pie Chart, (b) Column Chart, (c) Bar Chart. (Source: Authors)
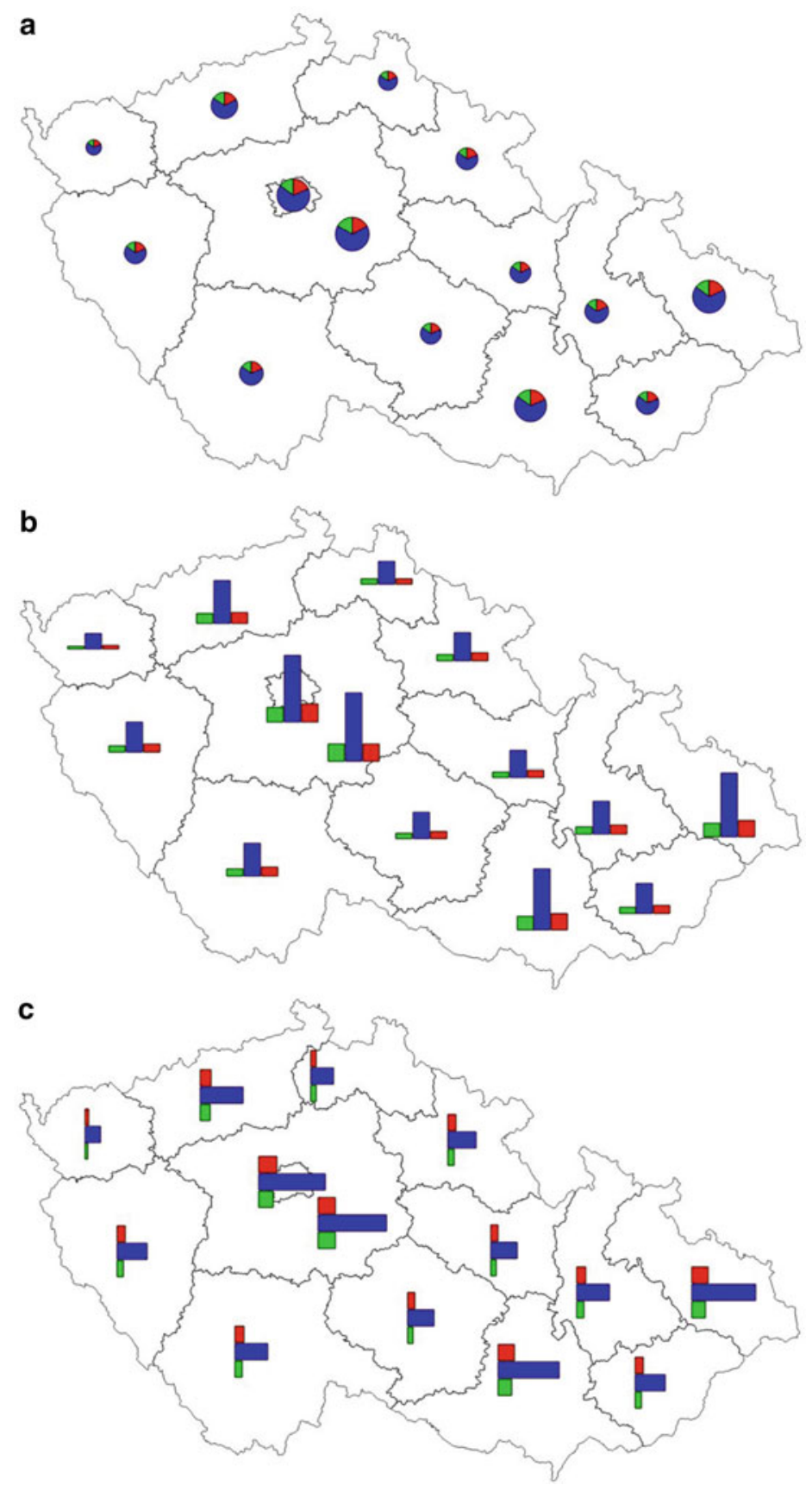

Additional map elements, such as a North arrow or Coordinates/Grid can be present as well.

The name of the map/Title represents the subject (WHAT), an area (WHERE) and a time specification (WHEN) of the mapped event. It is usually placed at the top of the map and often centred and written large enough to be readable from the distance. The word "map" is usually not used in the name as it is clear that it is a map. 


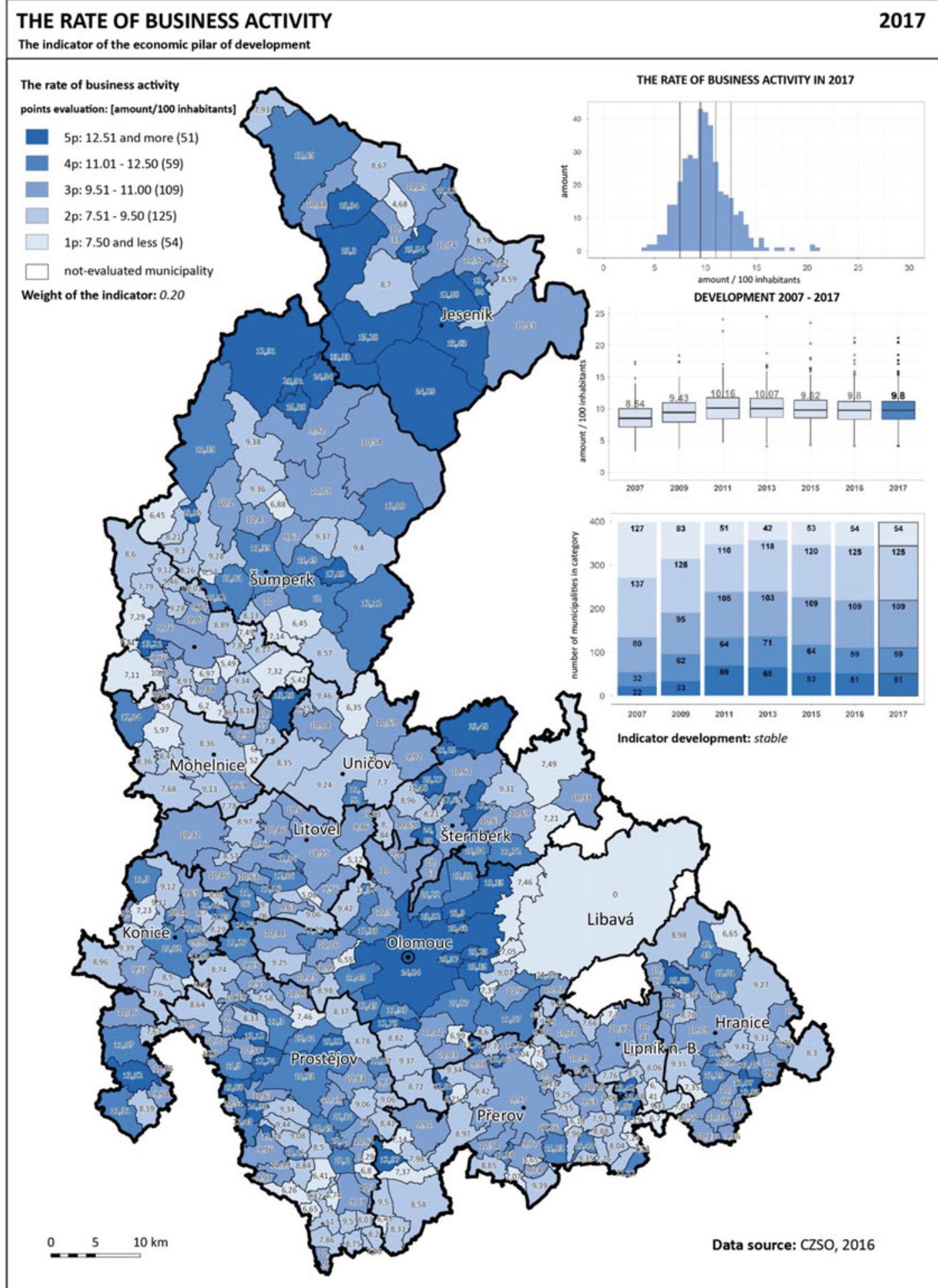

ANALYSIS OF HISTORICAL DEVELOPMENT OF THE ANALYTICAL MATERIAL FOR PLANING IN THE OLOMOUC REGION

Author: URBAN PLANNER s.r.o.

Fig. 9.13 Example of map with all obligatory components. (Source: Authors) 
Scale is a graphical and numeral ratio between distance on a map and the corresponding real distance on the ground. Graphical scale is more preferable as it maintains proportional compared to the numeral scale while copying (reducing or enlarging).

Creating a legend belongs to the most difficult tasks in the map creation and the following rules must be obeyed during the process:

- Completeness of the legend - every symbol from the map has to be in the legend and vice versa,

- Independence of the legend - every dissimilar object must also have a different symbol, it is also not possible that two different symbols would be assigned to the same object,

- Organisation of the legend - similar symbols are put into groups and the most important sets of elements are placed the highest,

- Structure of the legend - proportion, structure and colours in the legend have to be the same as used in the map,

- Comprehensiveness of the legend - the legend is simple, combined or complex combined according to the map character.

The map field is an area representing the map content itself which is limited by an inner map frame. It can have any shape or it is rectangular. It is either geometrically limited by a regular frame map (rectangular, square, etc.), or the frame border is an area (country, island) in case of individual territories.

The imprint contains a résumé of the information connected with the map creation - such as author, date of creation, data sources, publisher, etc.

Supplemental elements can include also logos, graphs, charts, figures, diagrams, text fields, smaller maps, etc.

\section{References}

Bertin, J. (1967). Semiology of graphics: Diagrams, networks, maps (Translation of "Sémiologie Graphique. Les Diagrammes, les Réseaux, les Cartes (1967)" by William J. Berg). Madison, Wisconsin.

Čapek, R., Mikšovský, M., \& Mucha, L. (1992). Geografická kartografie. Praha: SPN.

Field, K. (2018). Cartography : A compendium of design thinking for mapmakers.

ICA. (2018). Definitions. https://icaci.org/mission/. Accessed 27 Nov 2018.

QGIS.com. (2018). QGIS. http://qgis.com/

Robertson, N., Sanders, D. P., Seymour, P., \& Thomas, R. (1996). Efficiently four-coloring planar graphs. In Proceedings of the twenty-eighth annual ACM symposium on theory of computing - STOC '96 (pp. 571-575). New York: ACM Press.

Veverka, B., \& Zimová, R. (2008). Topografická a tematická kartografie. České vysoké učení technické v Praze. Praha: Stavební fakulta.

Voženílek, V., \& Kaňok, J. (2011). Metody tématické kartografie: vizualizace prostorových jevů. Olomouc: Univerzita Palckého v Olomouci.

Open Access This chapter is licensed under the terms of the Creative Commons Attribution 4.0 International License (http://creativecommons.org/licenses/by/4.0/), which permits use, sharing, adaptation, distribution and reproduction in any medium or format, as long as you give appropriate credit to the original author(s) and the source, provide a link to the Creative Commons licence and indicate if changes were made.

The images or other third party material in this chapter are included in the chapter's Creative Commons licence, unless indicated otherwise in a credit line to the material. If material is not included in the chapter's Creative Commons licence and your intended use is not permitted by statutory regulation or exceeds the permitted use, you will need to obtain permission directly from the copyright holder. 